\title{
CRESCIMENTO DE MUDAS DE Peltophorum dubium (Spreng.) Taub. SOB INTERFERÊNCIA DE PLANTAS ESPONTÂNEAS E FORRAGEIRAS
}

\author{
GROWTH OF SEEDLINGS OF Peltophorum dubium (Spreng.) Taub. UNDER \\ SPONTANEOUS AND FORAGING PLANTS INTERFERENCE
}

\section{Eduarda Soares Menezes ${ }^{1}$, Aline Ramalho dos Santos ${ }^{2}$, Marilia Dutra Massad ${ }^{3}$, Tiago Reis Dutra $^{4}$, Marcos Vinícius Miranda Aguilar ${ }^{5}$, Danielle Piuzana Mucida ${ }^{6}$}

${ }^{1,6}$ Universidade Federal dos Vales do Jequitinhonha e Mucuri, Diamantina, Minas Gerais, Brasil eduarda_menezs@hotmail.com\&dpiuzana@yahoo.com.br.

${ }^{2}$ Universidade Federal do Espírito Santo, Jerônimo Monteiro, Espírito Santo, Brasil, alineramalho13@hotmail.com

3, 4, 5 Instituto Federal de Educação, Ciência e Tecnologia do Norte de Minas Gerais, Salinas, Minas Gerais, Brasil - mariliamassad@yahoo.com.br, tiagoreisdutra@gmail.com \&aguilarmarcos2009@hotmail.com

\section{RESUMO}

O objetivo do trabalho foi avaliar a interferência de plantas espontâneas e forrageiras no crescimento inicial de mudas de Peltophorum dubium (Spreng.) Taub. As mudas foram produzidas em tubetes e transplantadas para os vasos aos 150 dias organizadas em delineamento experimental de blocos ao acaso, com quatro repetições e 13 tratamentos, sendo o desenvolvimento isolado ou em competição da canafístula com as seguintes espécies: Brachiaria decumbens, Brachiaria brizantha, Urochloa brizantha, Panicum maximum, Bidens pilosa e Cenchrus echinatus L., além da testemunha representada pela canafístula isolada. Cada vaso compôs uma parcela experimental, totalizando 52 vasos. Aos 60 dias de convivência foram mensurados a altura da parte aérea e diâmetro do coleto e quantificada a taxa de crescimento em altura (TCA), massa seca da parte aérea (MSPA), da raiz (MSR) e total (MST). A TCA da canafístula em cultivo isolado e em competição com P. maximum, C. echinatus, $B$. pilosa, $U$. brizantha e B. brizantha não apresentou diferença significativa. No plantio consorciado com $B$. brizantha $\mathrm{e}$ $B$. pilosa as mudas de canafístula obtiveram o maior incremento de MSPA e MST, semelhante à testemunha. Os menores incrementos em MSPA e MST foram obtidos na consorciação com $P$. maximum, $B$. decumbens, $U$. brizantha e $C$. echinatus. A espécie $B$. decumbens no plantio em competição com a canafístula apresentou maior produção de MSPA, MSR e MST, menor TCA e baixo acúmulo de MSPA e MST para as mudas da espécie florestal. Espécies espontâneas e forrageiras influenciam o crescimento inicial das mudas de $P$. dubium.

PALAVRAS-CHAVE: Canafístula, Competição interespecífica, Degradação, Ecologia florestal, Silvicultura.

\section{ABSTRACT}

The objective of this study was to evaluate the interference of spontaneous and forage plants on the initial growth of Peltophorum dubium (Spreng.) Taub seedlings. The seedlings were produced in tubes and transplanted to the vessels at 150 days, organized in a randomized block design with four replications and 13 treatments, being the isolated or competing development of the canafístula with the following species: Brachiaria decumbens, Brachiaria brizantha, Urochloa brizantha, Panicum maximum, Bidens pilosa and Cenchrus echinatus L., besides the control represented by the isolated canafístula. Each vessel composed an experimental plot, totaling 52 vessels. At 60 days, the height of the aerial part and diameter of the collection were measured and the growth rate in height (TCA), shoot dry mass (MSPA), root (MSR) and total (MST) were quantified. The TCA of the canafístula in cultivation isolated and in competition with P. maximum, C. echinatus, B. pilosa, U. brizantha and B. brizantha presented no significant difference. In the planting consortium with $B$. brizantha and $B$. pilosa the canafístula seedlings obtained the highest increase of MSPA and MST, similar to the control. The smallest increases in MSPA and MST were obtained in the intercropping with $P$. maximum, $B$. decumbens, $U$. brizantha and $C$. echinatus. The $B$. decumbens species in the planting in competition with the canafístula presented higher production of MSPA, MSR and MST, lower TCA and low accumulation of MSPA and MST for the seedlings of the forest species. Spontaneous and forage species influence the initial growth of $P$. dubium seedlings.

KEYWORDS: Canafístula, Interspecific competition, Degradation, Forest Ecology, Forestry. 


\section{INTRODUÇÃO}

A espécie Peltophorum dubium (Spreng.) Taub., conhecida popularmente por canafístula, pertencente à família Fabaceae e subfamília Caesalpinioideae. Espécie útil do cerrado, se destaca por seus usos múltiplos. É heliófita, classificada como pioneira, sendo frequente em todo domínio da floresta estacional decidual, floresta estacional semidecidual sub-montana e montana, podendo ser encontrada também em outras tipologias florestais como Cerradão, Chaco e Pantanal. Além de apresentar madeira de boa qualidade, a canafístula é recomendada para uso na construção civil, marcenaria, carpintaria e na indústria de papel e celulose (KLEIN et al., 2017). Pelo seu rápido crescimento e rusticidade, é comumente encontrada colonizando pastagens, ocupando clareiras e bordas de matas, sendo também utilizada para a composição de reflorestamentos mistos de áreas degradadas de preservação permanente, além de desempenho silvicultural aceitável quanto à sobrevivência e crescimento, e aptidão para programas de regeneração natural (CARNEVALI et al., 2016).

Apesar da grande importância das espécies nativas, seu crescimento e produção podem ser afetados negativamente em razão da competição interespecífica, na qual os organismos envolvidos utilizam o mesmo recurso, principalmente água, espaço, nutrientes e luz que podem limitar o crescimento, resultando em prejuízo ao desenvolvimento e sobrevivência da espécie menos competitiva.

A presença de plantas daninhas nos sistemas silviculturais pode causar interferências negativas, principalmente nos períodos iniciais do povoamento, devido à competição por água, luz e nutrientes, fator este que é desfavorável ao pleno desenvolvimento do componente florestal reduzindo o diâmetro, altura, número de folhas e área foliar (APARícIO et al., 2010; SOUZA et al., 2010; ASSIS et al., 2015).

$\mathrm{Na}$ recuperação de áreas degradadas, a presença de plantas espontâneas é considerada um dos problemas, principalmente no início do processo de regeneração natural ou artificial, onde pode ocorrer intensa competição entre as espécies (YAMASHITA et al., 2017). Plantas espontâneas apresentam alta rusticidade, resistência a pragas e doenças, habilidade de produzir grande número de sementes viáveis, facilidade de disseminação das sementes, rápida passagem da fase vegetativa para a reprodutiva, entre vários outros fatores inerentes a essas espécies (VASCONCELOS et al., 2012). O entendimento da interferência promovida pelas plantas espontâneas (ruderais) e forrageiras (gramíneas) sobre as culturas agrícolas e florestais se faz necessário em virtude do potencial agressivo daquelas sobre essas, principalmente na competição por água e nutrientes. Em áreas de reflorestamento, a presença dessas plantas torna-se indesejável quando o grau de competição resulta em redução do crescimento da espécie florestal (GANDINI et al., 2011). Por outro lado, do ponto de vista ecológico, a presença de várias espécies em algumas áreas, pode ser desejável, por favorecer a biodiversidade, promover maior cobertura do solo, reduzir a erosão, melhorar a estruturação e contribuir com o aporte de matéria orgânica do solo (DAVIDE et al., 2000).

Entretanto, a existência de informações relacionadas ao crescimento de espécies florestais em detrimento da competição com plantas espontâneas e forrageiras é incipiente. Além disso, as pesquisas sobre a interação dessas plantas constituem ferramentas necessárias para determinar a importância da ocorrência de espécies competidoras em sistemas de produção, suas formas de manejo e comportamento silvicultural das mesmas. Para responder esse questionamento, o presente estudo foi conduzido a partir da hipótese de que existem influências no crescimento da espécie arbórea $P$. dubium, quando em convivência com espécies espontâneas e forrageiras.

Diante disso, o objetivo do trabalho foi avaliar a interferência das plantas espontâneas e forrageiras sobre o crescimento inicial das mudas de $P$. dubium.

\section{MATERIAL E MÉTODOS}

\section{Área de estudo}

O experimento foi realizado no "Viveiro de Produção de Mudas Florestais" do Instituto Federal de Educação, Ciência e Tecnologia do Norte de Minas Gerais (IFNMG), Campus Salinas.

O município de Salinas está localizado entre $16^{\circ} 10^{\prime}$ $19^{\prime \prime}$ de latitude Sul e $42^{\circ} 17^{\prime} 30^{\prime \prime}$ de longitude Oeste, situado na mesorregião do Norte de Minas, com altitude média de $471 \mathrm{~m}$. O clima na região, de um modo geral, varia de subúmido a semiárido, classificado majoritariamente, segundo Köppen, como sendo Aw, de inverno seco e verão chuvoso (TOLEDO et al., 2009).

\section{Condução do experimento}

Foi adotado o delineamento experimental de blocos ao acaso, com quatro repetições e 13 tratamentos, sendo o desenvolvimento isolado ou em competição de $P$. 
dubium com as seguintes espécies: Brachiaria decumbens Stapf (braquiária), Brachiaria brizantha (Hochst. ex A. Rich.) Stapf (braquiarão), Urochloa brizantha (Hochst. ex A. Rich.) R. D. Webster (urocroa), Panicum maximum Hochst. ex A. Rich. (colonião), Bidens pilosa L. (picão preto) e Cenchrus echinatus L. (capim carrapicho), além da testemunha representada pela $P$. dubium isolada. Cada vaso compôs uma unidade experimental, totalizando 52 vasos.

As sementes de $P$. dubium foram coletadas em cinco matrizes localizadas no IFNMG, Campus Salinas, no ponto próximo a $22^{\circ} 13^{\prime} 16^{\prime \prime} \mathrm{S}$ e $54^{\circ} 48^{\prime} 2^{\prime \prime} \mathrm{O}$. Para superar a impermeabilidade do tegumento das sementes, foi realizada a superação da dormência por meio do método de imersão em água quente a $95^{\circ} \mathrm{C}$, e posterior repouso fora do aquecimento por 24 horas (DUTRA et al., 2013). As sementes foram desinfestadas em solução de hipoclorito de sódio (2\%) por 3 minutos, e semeadas em um número de 3 sementes por tubete com capacidade volumétrica de $180 \mathrm{~cm}^{3}$ preenchido com o substrato comercial Rohrbacher previamente adubado com $7,0 \mathrm{~g} \mathrm{dm}^{-3}$ de Osmocote ${ }^{\circledR}$ MiniPrill Controlled Realise 1906-10, com tempo estimado de liberação entre 3 a 4 meses. Os tubetes foram alocados em bandejas de polipropileno e dispostos em casa de vegetação coberta com filme plástico sob irrigação por nebulização intermitente, quatro vezes ao dia.

Aos 15 dias após semeadura (DAS) foi efetuado um primeiro raleio deixando-se duas plantas por tubete. Com 30 DAS um segundo raleio foi realizado, deixando-se uma muda por tubete, e as bandejas foram transferidas para o setor de crescimento à sombra coberto com tela sombrite de $50 \%$, onde foram mantidas sob irrigação com microaspersores, além de receberem fertirrigações semanais, com $6 \mathrm{~mL}^{\text {planta-1 }}{ }^{-1}$ de solução aquosa, contendo $4 \mathrm{~g} \mathrm{~L}^{-1}$ de sulfato de amônio, $10 \mathrm{~g} \mathrm{~L}^{-1}$ de superfosfato simples, $4 \mathrm{~g} \mathrm{~L}^{-1}$ de cloreto de potássio e $1 \mathrm{~g} \mathrm{~L}^{-1}$ de FTE BR12 ( $9 \% \mathrm{Zn}, 3 \% \mathrm{Fe}, 2 \% \mathrm{Mn}, 0,1 \% \mathrm{Mo}, 1,8 \% \mathrm{~B}, 0,8 \% \mathrm{Cu}$ ).

Para instalação do experimento em vasos, trinta e cinco dias anteriores ao transplantio das mudas de P. dubium, foi realizada a coleta e preparo do solo. 0 mesmo foi retirado de áreas próximas ao "Viveiro de Produção de Mudas Florestais" do IFNMG, Campus Salinas, da camada de 20 a $40 \mathrm{~cm}$ de profundidade, sendo caracterizado quimicamente conforme Empresa Brasileira de Pesquisa em Agropecuária - EMBRAPA (1997) (Tabela 1).

Com os resultados encontrados para o solo coletado (Tabela 1), não houve a necessidade de realização de calagem para correção da acidez. Dois dias antes do transplantio das mudas para os vasos aplicou-se, por solução, $100 \mathrm{mg} \mathrm{dm}^{-3}$ de $\mathrm{N}, 200 \mathrm{mg} \mathrm{dm}^{-3}$ de $P$, $100 \mathrm{mg} \mathrm{dm}^{-3}$ de $\mathrm{K}$ e $40 \mathrm{mg} \mathrm{dm}^{-3}$ de $\mathrm{S}$, tendo como fontes [( $\left.\left.\mathrm{NH}_{4}\right)_{2} \mathrm{SO}_{4}\right]$ (sulfato de amônio), $\mathrm{NaH}_{2} \mathrm{PO}_{4} \cdot \mathrm{H}_{2} \mathrm{O}$ (fosfato de sódio), $\mathrm{KH}_{2} \mathrm{PO}_{4}$ (potássio hidrogenofosfato) e $\mathrm{K}_{2} \mathrm{SO}_{4}$ (sulfato de potássio), respectivamente. Em sequência aplicou-se também uma solução de micronutrientes nas seguintes doses: $0,81 \mathrm{mg} \mathrm{dm}^{-3}$ de $\mathrm{B}\left(\mathrm{H}_{3} \mathrm{BO}_{3}\right.$; ácido bórico), $1,33 \mathrm{mg} \mathrm{dm}{ }^{-3}$ de $\mathrm{Cu}\left(\mathrm{CuSO}_{4} .5 \mathrm{H}_{2} \mathrm{O}\right.$; sulfato de cobre), $0,15 \mathrm{mg} \mathrm{dm}^{-3}$ de $\mathrm{Mo}\left[\left(\mathrm{NH}_{4}\right)_{6} \mathrm{Mo}_{7} \mathrm{O}_{24} .4 \mathrm{H}_{2} \mathrm{O}\right)$; molibdato de amônio], 3,66 mg dm ${ }^{-3}$ de $\mathrm{Mn}\left(\mathrm{MnCl}_{2} . \mathrm{H}_{2} \mathrm{O}\right.$; cloreto de manganês) e 4,0 mg dm${ }^{-3}$ de $\mathrm{Zn}\left(\mathrm{ZnSO}_{4} .7 \mathrm{H}_{2} 0\right.$; sulfato de zinco), conforme Dutra et al. (2017).

Tabela 1. Características químicas e classe textural do solo utilizado como substrato na produção das mudas antes da aplicação dos tratamentos.

\begin{tabular}{|c|c|}
\hline Características & Solo \\
\hline pH em água & 6,0 \\
\hline Matéria Orgânica (dag kg-1) & 2,37 \\
\hline Fósforo (mg kg-1) & 10,25 \\
\hline Potássio (mg kg-1) & 157 \\
\hline Cálcio $\left(\mathrm{cmol}_{\mathrm{c}} \mathrm{dm}^{-3}\right)$ & 3,9 \\
\hline Magnésio $\left(\mathrm{cmol}_{\mathrm{c}} \mathrm{dm}^{-3}\right)$ & 1,6 \\
\hline Acidez potencial $(\mathrm{H}+\mathrm{Al})\left(\mathrm{cmol}_{\mathrm{c}} \mathrm{dm}^{-3}\right)$ & 1,33 \\
\hline Alumínio $\left(\mathrm{cmol}_{\mathrm{c}} \mathrm{dm}^{-3}\right)$ & 0 \\
\hline Capacidade efetiva de troca de cátions $(\mathrm{t})\left(\mathrm{cmol}_{\mathrm{c}} \mathrm{dm}^{-3}\right)$ & 5,9 \\
\hline Capacidade de troca de cátions a $\mathrm{pH} 7(\mathrm{~T})\left(\mathrm{cmol}_{\mathrm{c}} \mathrm{dm}^{-3}\right)$ & 7,23 \\
\hline Soma de bases (SB) $\left(\mathrm{cmol}_{\mathrm{c}} \mathrm{dm}^{-3}\right)$ & 5,9 \\
\hline Saturação por alumínio (m) (\%) & 0 \\
\hline Saturação por bases (V) (\%) & 82 \\
\hline Areia Grossa (dag kg-1) & 7,6 \\
\hline Areia Fina $\left(\right.$ dag $\left.\mathrm{kg}^{-1}\right)$ & 52,4 \\
\hline Silte (dag kg-1) & 18,0 \\
\hline Argila $\left(\right.$ dag kg $\left.^{-1}\right)$ & 22,0 \\
\hline
\end{tabular}

As mudas de P.dubium, aos 150 DAS foram transplantadas para vasos de polietileno com capacidade para $18 \mathrm{dm}^{3}$, preenchidos previamente com o solo peneirado previamente adubado, e organizadas em canteiros em área de crescimento protegido de irrigação. Durante todo o período experimental a umidade do solo foi mantida próxima de $60 \%$ da capacidade de campo, procedendo-se com o monitoramento diário usando-se uma balança, para o controle, tendo como base a massa de solo e água por vaso. Aos 21 dias após o transplantio das mudas, foi realizada a semeadura de 30 sementes das espécies espontâneas e forrageiras por vaso. Após a emergência, houve o desbaste deixando-se uma planta por vaso. 


\section{Parâmetros avaliados}

No transplantio das mudas e aos 60 dias de convivência em vasos foram mensurados na $P$. dubium a altura da parte aérea $(\mathrm{H} ; \mathrm{cm})$, diâmetro de coleto (DC; $\mathrm{mm}$ ) e a taxa de crescimento em altura (TCA), obtida a partir da solução analítica da relação TCA=H/MSPA (SILVA et al., 2009). A altura da parte aérea das mudas foi realizada com o auxílio de uma régua milimetrada posicionada no nível do solo até o meristema apical das mesmas. O diâmetro de coleto foi medido através do uso de um paquímetro digital da marca Western.

Em seguida, todas as plantas de $P$. dubium e das demais espécies estudadas foram colhidas e separadas em parte aérea e sistema radicular, lavadas em água corrente e secas em estufa com circulação forçada de ar, a aproximadamente $65^{\circ} \mathrm{C}$, por 72 horas onde atingiram o peso constante para realização das avaliações de massa seca da parte aérea (MSPA; g planta-1 ${ }^{-1}$ ), massa seca da raiz (MSR; $g$ planta-1) e massa seca total $\left(\mathrm{MST}=\mathrm{MSPA}+\mathrm{MSR} ; \mathrm{g}\right.$ planta $\left.^{-1}\right)$. As análises foram realizadas utilizando-se o pacote ExpDes.pt (FERREIRA et al., 2013) do software livre $R$ (R CORE TEAM, 2015). A comparação entre as médias dos tratamentos foi feita através do teste de Tukey, adotando-se o nível de $5 \%$ de significância.

\section{RESULTADOS E DISCUSSÃO}

Os efeitos significativos na taxa de crescimento em altura (TCA) foram observados para as mudas de P. dubium em plantio isolado ou em competição (Tabela 2). A maior TCA foi encontrada em plantio isolado, entretanto, não houve diferença estatística para o plantio consorciado com C. echinatus, B. pilosa, P. maximum, $U$. brizantha $e$ B. brizantha, demonstrando a baixa interferência que essas espécies propiciaram no crescimento em altura dessa espécie arbórea, em função de fatores como tamanho do sistema radicial, hábito de crescimento e condições encontradas no local.

A baixa interferência observada para a TCA no convívio das espécies $C$. echinatus, $B$. pilosa, $P$. maximum, $U$. brizantha e $B$. brizantha com as mudas de $P$. dubium (Tabela 2) indica que a competição por água e recursos do solo não foram fatores limitantes para o crescimento em altura das mudas, demonstrando que essas plantas espontâneas e forrageiras não exerceram inibição na absorção de recursos para a espécie arbórea.
Tabela 2. Taxa de crescimento em altura (TCA) de mudas de Peltophorum dubium em competição com plantas espontâneas e forrageiras.

\begin{tabular}{cl}
\hline Tratamentos & TCA \\
\hline Testemunha & $0,38 \mathrm{a}$ \\
Brachiaria brizantha & $0,37 \mathrm{ab}$ \\
Urochloa brizantha & $0,35 \mathrm{ab}$ \\
Bidens pilosa & $0,34 \mathrm{ab}$ \\
Cenchrus echinatus $L$. & $0,33 \mathrm{ab}$ \\
Panicum maximum & $0,27 \mathrm{ab}$ \\
\hline Brachiaria decumbens & $0,22 \mathrm{~b}$ \\
\hline CV (\%) & 20,2 \\
\hline
\end{tabular}

Médias seguidas da mesma letra na coluna não diferem entre si pelo teste Tukey a $5 \%$ de significância.

Em contrapartida, a espécie $B$. decumbens promoveu à P. dubium a menor TCA (Tabela 2), corroborando com Ikeda et al. (2013) que afirmam que a espécie se torna uma planta indesejável, quando utilizada em áreas que não sejam de pastagens, em função de sua rusticidade e do difícil controle. A espécie $B$. decumbens, trata-se de uma excelente forrageira, perene e com grande produção de massa foliar de boa qualidade, resistente ao pastejo e ao pisoteio (SANTANA et al., 2010). Além disso, Toledo et al. (2000) ressaltam a agressividade e o potencial colonizador dessa espécie forrageira invasora comprometendo os processos de regeneração natural.

Em plantios de Eucalyptus sp. e Pinus sp., a $B$. decumbens vêm-se tornando problemática, devido à elevada agressividade e o difícil controle, mesmo em baixas densidades. Ela interfere no desenvolvimento da cultura, levando a perdas na qualidade e quantidade do produto colhido, além de ocasionar a redução da eficiência do trabalho e consequentemente, o aumento do custo operacional nas áreas de produção (PEREIRA et al., 2014). Vale ressaltar, que a interferência ocorrida neste trabalho foi entre um indivíduo da planta competidora e uma muda de P. dubium, no entanto, em condições de campo a presença de densidades variáveis da espécie numa mesma área podem causar perdas significativas se não for realizado o manejo adequado, devido ao esgotamento mais rápido dos recursos do meio.

Quando avaliada as variáveis MSPA e MST das mudas de $P$.dubium observou-se que o plantio isolado apresentou as maiores produções, não se diferenciando estatisticamente do plantio consorciado com $B$. brizantha e $B$. pilosa, indicando que a convivência com essas espécies não promoveu prejuízo ao desenvolvimento inicial de $P$. dubium para produção de massa seca (Tabela 
3). Os menores incrementos em para ambas as variáveis foram obtidos na consorciação com $P$. maximum, $B$. decumbens, $U$. brizantha e $C$. echinatus. A redução na acumulação de MST está relacionada com a menor produção de MSPA da espécie em convivência com essas espécies espontâneas e forrageiras.

Tabela 3. Produção de massa seca da parte aérea (MSPA) e massa seca total (MST) de mudas de Peltophorum dubium em plantio isolado ou em competição com plantas espontâneas e forrageiras.

\begin{tabular}{|c|c|c|c|}
\hline \multirow{3}{*}{ Tratamentos } & MSPA & MSR & MST \\
\hline & \multicolumn{3}{|c|}{............ g planta ${ }^{-1} \ldots \ldots \ldots \ldots$} \\
\hline & \multicolumn{3}{|c|}{ Plantio isolado } \\
\hline B. decumbens & $43,18 \mathrm{a}$ & $8,81 a b$ & $52,00 \mathrm{a}$ \\
\hline B. brizantha & $30,99 a b$ & $8,44 a b$ & $39,42 a b$ \\
\hline U. brizantha & 39,09 a & $8,97 a b$ & $48,05 a b$ \\
\hline P. maximum & 39,29 a & $17,26 a$ & $56,55 a$ \\
\hline B. pilosa & $13,92 \mathrm{~b}$ & $3,32 \mathrm{~b}$ & $17,25 \mathrm{~b}$ \\
\hline C. echinatus & $30,04 a b$ & $8,38 a b$ & $38,42 \mathrm{ab}$ \\
\hline \multirow[t]{2}{*}{ CV (\%) } & 32,2 & 45,6 & 33,08 \\
\hline & \multicolumn{3}{|c|}{ Plantio em competição } \\
\hline B. decumbens & $15,24 a$ & $5,10 \mathrm{a}$ & $20,34 \mathrm{a}$ \\
\hline B. brizantha & $5,31 a b$ & $2,19 b$ & $7,5 \quad b$ \\
\hline U. brizantha & $10,38 a b$ & $5,68 \mathrm{a}$ & $16,06 \mathrm{ab}$ \\
\hline P. maximum & $9,02 a b$ & $2,79 b$ & $11,81 a b$ \\
\hline B. pilosa & 1,91 & $1,96 \mathrm{~b}$ & 3,87 \\
\hline C. echinatus & $8,76 a b$ & 6,64 a & $15,41 a b$ \\
\hline CV (\%) & 35,7 & 29,3 & 38,6 \\
\hline
\end{tabular}

Médias seguidas da mesma letra na coluna não diferem entre si pelo teste Tukey a $5 \%$ de significância.

As espécies $B$. decumbens, $P$. maximum e $U$. brizantha apresentaram as maiores médias para MSPA em cultivo isolado, entretanto, não se diferenciaram estatisticamente de $B$. brizantha e $C$. echinatus. Para MST destacaram-se $P$. maximum e $B$. decumbens, produto das elevadas produções de MSPA e MSR. Além disso, essas espécies não se diferenciaram estatisticamente das espécies $C$. echinatus, B. brizantha e $U$. brizantha para essa variável (Tabela 4). As espécies $B$. decumbens, $U$. brizantha, $P$. maximum e $C$. echinatus proporcionaram às mudas de $P$. dubium nas avaliações de MSPA e MST os menores incrementos (Tabela 3), evidenciando o efeito negativo do consórcio dessas espontâneas com a espécie arbórea.

Em competição com a P. dubium (Tabela 4), $B$. decumbens apresentou valores de MSPA, MSR e MST superiores, se diferenciando significativamente apenas de
B. pilosa para MSPA; B. brizantha, P. maximum e B. pilosa para MSR; B. brizantha e B. pilosa para MST. Esses resultados evidenciam que as condições de desenvolvimento para as espécies espontâneas foram favoráveis quando em consórcio com a espécie florestal, demonstrando a competição que essas plantas exercem no ambiente.

Tabela 4. Produção de massa seca da parte aérea (MSPA), massa seca da raiz (MSR) e massa seca total (MST) de plantas espontâneas e forrageiras em competição.

\begin{tabular}{ccc}
\hline Mratamentos & MSPA & MST \\
\hline & ......g.planta ${ }^{-1} \ldots .$. \\
\hline B. decumbens & $28,3 \mathrm{~b}$ & $38,7 \mathrm{~b}$ \\
\hline B. brizantha & $37,0 \mathrm{ab}$ & $49,1 \mathrm{ab}$ \\
U. brizantha & $29,0 \mathrm{~b}$ & $41,0 \mathrm{~b}$ \\
\hline P. maximum & $28,3 \mathrm{~b}$ & $38,3 \mathrm{~b}$ \\
B. pilosa & $35,0 \mathrm{ab}$ & $45,9 \mathrm{ab}$ \\
\hline C. echinatus & $30,7 \mathrm{~b}$ & $39,1 \mathrm{~b}$ \\
\hline Testemunha & $42,2 \mathrm{a}$ & $53,8 \mathrm{a}$ \\
\hline CV (\%) & 20,4 & 13,9 \\
\hline
\end{tabular}

Médias seguidas da mesma letra na coluna não diferem entre si pelo teste Tukey a $5 \%$ de significância.

Na análise da MSPA e MST das mudas de $P$. dubium (Tabela 3) observou-se que as mudas em plantio isolado e competição com as espécies $B$. brizantha e $B$. pilosa não se diferenciaram estaticamente, resultados esses que corroboram com Melotto et al. (2009) que indicaram a $P$. dubium como sendo a espécie que obteve a melhor combinação de massa seca da parte aérea no plantio em pastagens de $B$. brizantha na região do cerrado, atribuindo a característica típica de pioneira heliófita, associada à adaptação às condições edafoclimáticas locais, como fatores importantes para o bom desempenho. Em estudo semelhante, com a espécie Corymbia citriodora em um período de convivência de 60 dias, e as nativas: Dypterix alata Vogel, Astronium concinnum Schott ex Spreng, Hymenaea stigonocarpa Mart. ex Hayne em 120 dias de convivência, a presença de plantas de B. brizantha não influenciou o desenvolvimento inicial das mudas para as variáveis MSPA, MSR e MST (BOCCHESE et al., 2007).

Entretanto, para essas variáveis a presença de $P$. maximum, B. decumbens, $U$. brizantha e $C$. echinatus influenciou o crescimento da P.dubium (Tabela 3), promovendo os menores incrementos de biomassa. Segundo Mantoani et al. (2012), o capim-colonião (Panicum maximum Jacq.) prejudica significativamente a 
instalação de outras espécies, por se tornar uma barreira física e competir com as espécies nativas, influenciando preferencialmente as espécies arbóreas.

Barducci et al. (2009) ressaltam que essa espécie possui um sistema radicular vigoroso e profundo, elevada tolerância a deficiência hídrica e absorção de nutrientes em camadas mais profundas do solo, desenvolvendo-se em condições ambientais adversas. Gobbi et al. (2011), afirmam que $B$. decumbens quando cultivada com uma espécie arbórea, promove um sombreamento que proporciona o aumento na taxa de alongamento foliar da forrageira, resultando em maior área foliar para captação de luz em ambiente de reduzida luminosidade. Resultados de pesquisas semelhantes sinalizam para essas variáveis efeito negativo da $B$. decumbens no desenvolvimento de mudas de Eucalyptus grandis (SOUZA et al., 2003).

A diferença significativa observada em plantio isolado, ao analisar a MSPA, MSR e MST das espécies espontâneas e forrageiras em plantio isolado ou em competição com mudas de $P$. dubium (Tabela 4), evidencia o potencial agressivo das espécies $B$. decumbens, $P$. maximum, $U$. brizantha, B. brizantha e C. echinatus. Rosa et al. (2011) mostram que o extrato de $P$. maximum não prejudicou a germinação das sementes de espécies nativas estudadas (P. dubium e Parapiptadenia rigida (Benth.) Brenam) e o único efeito observado foi estimulatório, concluindo que o efeito exercido sobre essas espécies não decorre de alelopatia e sim de competição, conforme demonstra o presente estudo, verificado nos valores médios reduzidos de MSPA e MST das mudas de $P$. dubium em competição (Tabela 3) e elevados incrementos de produção de massa para $P$. maximum em plantio isolado e em competição (Tabela 4).

As espécies de brachiaria em diferentes arranjos de sistema agrossilvipastoril prejudicou o desenvolvimento do eucalipto em fileiras com milho para todas as variáveis ecofisiológicas estudadas por Santos et al. (2017). No estudo, a espécie $B$. decumbens em competição com as mudas de $P$. dubium apresentou os maiores incrementos em MSPA, MSR e MST, se diferenciando estaticamente apenas da $B$. pilosa nas variáveis mencionadas e da $B$. brizantha para a MSR e MST (Tabela 4). Esse resultado evidencia os prejuízos ocasionados às mudas de P. dubium para a TCA (Tabela 2), MSPA e MST (Tabela 3).

A $B$. decumbens já vem sendo discutida em diversos programas de restauração em áreas degradadas, principalmente no bioma Cerrado, onde o seu controle é imprescindível, sendo apontado como um dos principais desafios para o sucesso das técnicas e um dos principais custos elencados na recuperação. $U$. brizantha também requer atenção, sendo apontada por apresentar redução na fotossíntese e transpiração de culturas em função do aumento da densidade e do convívio com essas espécies (BARROS et al., 2017).

Já a espécie $B$. pilosa, apresentou as menores produções de MSPA, MSR e MST em plantio isolado, porém, não se diferiu significativamente das espécies $C$. echinatus, $B$. brizantha para essas variáveis, $U$. brizantha para MSR e MST e $B$. decumbens para MSR (Tabela 4). Comportamento esse, que favoreceu o incremento de MSPA e MST nas mudas de P. dubium (Tabela 3), entretanto, Martins et al. (2015) constataram que a $B$. pilosa foi a espécie espontânea que apresentou maior potencial de competição com as mudas de Olea europaea L. Assim, destaca-se a necessidade do conhecimento da interferência das espécies espontâneas e forrageiras no crescimento das mudas florestais.

\section{CONCLUSÕES}

Espécies espontâneas e forrageiras influenciam o crescimento inicial das mudas de $P$. dubium, nas variáveis MSPA, MSR, MST e TCA. A espécie $B$. decumbens causou efeitos negativos para as mudas de $P$. dubium em todas as variáveis analisadas.

Estudos semelhantes devem ser aplicados com diversas espécies, subsidiando estudos de recuperação de áreas degradadas e na implantação de espécies arbóreas em áreas com presença das espontâneas e forrageiras.

\section{AGRADECIMENTOS}

À Fundação de Amparo à Pesquisa do Estado de Minas Gerais (FAPEMIG) pela concessão da bolsa de pesquisa à primeira autora durante o ano de 2015. À CAPES Prodoutoral pela concessão de bolsas ao 3 ㅇ e 4을 autores. $O$ presente trabalho foi realizado com apoio da Coordenação de Aperfeiçoamento de Pessoal de Nível Superior - Brasil (CAPES) - Código de Financiamento 001.

\section{REFERÊNCIAS}

APARÍCIO, P.S. et al. Controle da matocompetição em plantios de dois clones de Eucalyptus $\times$ Urograndis no Amapá. Ciência Florestal, v.20, n.3, p.381-390, 2010.

ASSIS, H.L. et al. Haloxifope-P-Metílico para controle de Brachiaria decumbens na cultura do eucalipto. Cerne, v.21, n.4, p.553-560, 2015.

BARDUCCI, R.S. et al. Produção de Brachiaria brizantha e Panicum maximum com milho e adubação nitrogenada. Archivos de Zootecnia, v.58, n.222, p.211-222, 2009. 
BARROS, R.E. et al. Physiological response of maize and weeds in coexistence. Planta Daninha, v.35, p.01-08, 2017.

BOCCHESE, R.A. et al. Avaliação da competição entre Brachiaria brizantha cv. Marandu, espécies arbóreas nativas do Cerrado e Eucalyptus citriodora. Revista Brasileira de Biociências, v.5, p.153-155, 2007.

CARNEVALI, N.H.S. et al. Sobrevivência e crescimento inicial de espécies arbóreas nativas implantadas em pastagem degradada. Revista Floresta, v.46, n.2, p.277-286, 2016.

DAVIDE, A.C. et al. Restauração de matas ciliares. Informe Agropecuário, v.21, n.207, p.65-74, 2000.

DUTRA, T.R. et al. Superação de dormência e substratos alternativos com serragem na germinação e crescimento inicial de mudas de Peltophorum dubium (Spreng.) Taub. Agropecuária Científica no Semiárido, v.13, n.2, p.113-120, 2017.

DUTRA, T.R. et al. Substratos alternativos e métodos de quebra de dormência para produção de mudas de canafístula. Revista Ceres, v.60, n.1, p.72-78, 2013.

FERREIRA, E.B. et al. ExpDes.pt: Experimental designs package. R package version (1. 1. 2). 2013. Disponível em: https://cran.rproject.org/web/packages/ExpDes.pt/index.htm.

GANDINI, E.M.M. et al. Capacidade competitiva do jatobá com adubos verdes, forrageiras e plantas daninhas. Planta Daninha, v.29, p.991-999, 2011.

GOBBI, K.F. et al. Área foliar específica e anatomia foliar quantitativa do capim-braquiária e do amendoim-forrageiro submetidos a sombreamento. Revista Brasileira Zootecnia, v.40, n.7, p.1436-1444, 2011.

IKEDA, F.S. et al. Emergência e crescimento inicial de cultivares de Urochloa em diferentes profundidades de semeadura. Planta Daninha, v.31, n.1, p.71-78, 2013.

KLEIN, K. et al. Desenvolvimento inicial de plântulas de Peltophorum dubium (Spreng.) Taub. sob protetores físicos com diferentes níveis de luminosidade. Nativa, v.5, n.3, p.92-100, 2017.

MANTOANI, M.C. et al. Efeitos da invasão por Panicum maximum Jacq. e do seu controle manual sobre a regeneração de plantas lenhosas no sub-bosque de um reflorestamento. Revista Semina: Ciências Biológicas e da Saúde, v.33, n.1, p.97110, 2012.

MARTINS, L.M. et al. Crescimento inicial de mudas de oliveira em competição com plantas daninhas. Revista Agrarian, v.8, n.28, p.124-132, 2015.

MELOTTO, A. et al. Sobrevivência e crescimento inicial em campo de espécies florestais nativas do Brasil central indicadas para sistemas silvipastoris. Revista Árvore, v.33, n.3, p.425-432, 2009.

PAULA, J.L.; DUARTE, M.N. Manual de métodos de análise de solos. 2.ed. Embrapa: Centro Nacional de Pesquisa de Solos, 1997. Disponível em: https://www.agencia.cnptia.embrapa.br/
Repositorio/Manual+de+Metodos_000fzvhotqk02wx5ok0q43a0 ram31wtr.pdf.

PEREIRA, F.C.M. et al. Interferência de plantas daninhas: Conceitos e exemplos na cultura do Eucalipto. Journal of Agronomic Sciences, v.3, p.236-255, 2014.

R CORE TEAM. R: A language and environment for statistical computing. Vienna: R Foundation for Statistical Computing, 2015. Disponível em: http://www.R-project.org

ROSA, D.M. et al. Potencial Alelopático de Panicum maximum JACQ sobre a Germinação de Sementes de Espécies Nativas. Floresta e Ambiente, v.18, n.2, p.198-203, 2011.

SANTANA, G.S. et al. Atributos químicos, produção e qualidade do capim braquiária em solos corrigidos com calcário e escória silicatada. Revista Ceres, v.57, n.3, p.377-382, 2010.

SANTOS, M.V. et al. Brachiaria physiological parameters in agroforestry systems. Ciência Rural, v.47, n.5, p.01-06, 2017.

SILVA, T.G.F. et al. Crescimento do girassol ornamental cultivado em ambiente protegido sob diferentes níveis de condutividade elétrica de fertirrigação. Revista Ceres, v.56, n.5, p.602-610, 2009.

SOUZA, M.C. et al. Interference of weed community on Eucalyptus grandis second coppice plants. Scientia Forestalis, v.38, n.85, p.63-71, 2010.

SOUZA, L.S. et al. Efeito alelopático de plantas daninhas e concentrações de capim-braquiária (Brachiaria decumbens) no desenvolvimento inicial de eucalipto (Eucalyptus grandis). Planta Daninha, v.21, n.3, p.343-354, 2003.

TOLEDO, L.O. et al. Análise multivariada de atributos pedológicos e fitossociológicos aplicada na caracterização de ambientes de cerrado no norte de Minas Gerais. Revista Árvore, v.33, n.5, p.957-968, 2009.

TOLEDO, R.E.B. et al. Efeito de períodos de controle de plantas daninhas sobre o desenvolvimento inicial de plantas de eucalipto. Planta Daninha, v.18, n.3, p.395-404, 2000.

VASCONCELOS, M.C.C. et al. Interferência de plantas daninhas sobre plantas cultivadas. Agropecuária Científica no Semiárido, v.8, n.1, p.01-06, 2012.

YAMASHITA, O.M. et al. Interferência de subdoses de glyphosate no desenvolvimento de plantas jovens de nim. Nativa, v.5, n.3, p.163-168, 2017. 